\title{
Relações públicas no capitalismo cognitivo
}

\author{
Public relations in cognitive capitalism
}

\section{Las relaciones públicas en el capitalismo cognitivo}

\section{Cicilia Maria Krohling Peruzzo}

- Pós-doutora pela Universid Autónoma de México

- Doutora em Ciências da Comunicação pela Escola de Comunicações e Artes da Universidade de São Paulo

- Mestre em Comunicação Social pela Universidade Metodista de São Paulo (Umesp)

- Graduada em Comunicação Social - Relações Públicas pela Faculdade de Comunicação Social Anhembi

- Professora do Programa de Pós-Graduação em Comunicação Social da Umesp

- Editora de Intercom - Revista Brasileira de Ciência da Comunicação

- Ex-presidente da Sociedade Brasileira de Estudos Interdisciplinares da Comunicação (Intercom), de 1999 a 2002

- Autora dos livros: Televisão comunitária: dimensão pública e participação cidadã na mídia local; Comunicação nos movimentos populares: a participação da construção da cidadania (3. ed., 2004); Relações públicas no modo de produção capitalista (4. ed., 2004)

- Organizadora, entre outros, dos livros: Vozes cidadãs: aspectos teóricos e análises de experiências de comunicação popular sindical na América Latina; Comunicação para a cidadania; Mídia, regionalismo e cultura; Sociedade da informação e novas mídias: participação ou exclusão?; Comunicación y movimientos populares: cuales redes?; Comunicação e multiculturalismo; Comunicação e culturas populares

-kperuzzo@uol.com.br 
Resumo

O objetivo deste ensaio é apontar brevemente os principais aspectos teóricos sobre as mudanças paradigmáticas no capitalismo, além de aproximar a questão das relações públicas refletindo sobre a efetividade ou não de seus pressupostos quanto ao potencial de colaborar para aumentar a potenciação das forças produtivas. As mudanças engendradas pelo capitalismo cognitivo se revelam em múltiplas dimensões, entre elas o trabalho imaterial, as quais instituem novos paradigmas nas relações capital-trabalho, mas não extraem da atividade de relações públicas o seu poder de contribuir para estabelecer relações de cumplicidade entre a organização e os seus "colaboradores" e de angariar consensos na sociedade.

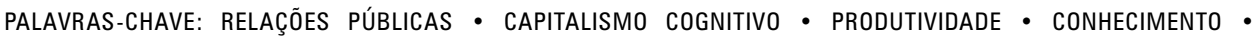
TRABALHO IMATERIAL

\section{Abstract}

The objective of this essay is of briefly pointing out the principal theoretical aspects relative to the paradigmatic changes in capitalism, as well as addressing the question of whether or not public relations reflects on the effectiveness of its assumptions as to the potential of collaborating to increase the potentiality of the productive forces. The changes engendered by cognitive capitalism are disclosed in multiple dimensions, among which immaterial work, which create new paradigms in the capital-labor relations, but do not extract from the public relations activity its power of contributing to establish relations of complicity between the organization and its "collaborators" and of recruiting consensus in the society.

KEYWORDS: PUBLIC RELATIONS • COGNITIVE CAPITALISM • PRODUCTIVITY • KNOWLEDGE • IMMATERIAL WORK

Resumen

El objetivo de este ensayo es apuntar brevemente los principales aspectos teóricos sobre los cambios paradigmáticos en el capitalismo, además de aproximar la cuestión de las relaciones públicas. Para ello, se reflexiona sobre la efectividad o no de sus presupuestos con relación al potencial de colaborar para aumentar la potenciación de las fuerzas productivas. Los cambios engendrados por el capitalismo cognitivo se revelan en múltiples dimensiones (entre ellas, el trabajo inmaterial), que instituyen nuevos paradigmas en las relaciones capital-trabajo, pero no extraen de la actividad de relaciones públicas su poder de contribuir a establecer relaciones de complicidad entre la organización y sus "colaboradores" y de buscar consensos en la sociedad.

PALABRAS ClAVE: RELACIONES PÚBlicAS • CAPITALISMO COGNITIVO • PRODUCTIVIDAD • CONOCIMIENTO • TRABAJO INMATERIAL 
$\mathrm{N}^{\mathrm{o}}$ o contexto das mudanças do modo de produção capitalista parece-nos oportuno refletir como as relações públicas se situam nesse novo cenário e sobre quais seriam as alterações que podem ser percebidas quanto às finalidades de seu emprego pelas organizações. Porém, este texto se configura como um ensaio, ou seja, procura levantar questões para o debate e que requerem investidas mais completas. Trata-se de tema complexo, impossível de ser esgotado no número de páginas exigidas para apresentar trabalhos em congressos. Assim, dentro dos limites previsíveis, o objetivo é apontar brevemente os principais aspectos teóricos sobre as mudanças paradigmáticas no capitalismo, além de aproximar o tema das relações públicas no sentido de refletir sobre a efetividade ou não de seus pressupostos quanto ao potencial de contribuir para aumentar a cooperação, a produtividade e a potenciação das forças produtivas, especialmente do trabalho.

O estudo se baseia em pesquisa bibliográfica e usa o materialismo histórico-dialético como referencial interpretativo. Trabalhamos com duas hipóteses, sendo que a primeira é a de que as relações públicas são utilizadas pelas empresas visando criar ambiente propenso ao aumento da cooperação e da produtividade do trabalhador, além obter a colaboração de outros públicos em torno das estratégias empresariais. A segunda hipótese pressupõe que as mudanças paradigmáticas do capitalismo afetam as relações capital-trabalho, embora não descaracterizem o papel dos instrumentos de comunicação que visam estabelecer um clima propício à produtividade do trabalho, mesmo que sobre bases operativas como aquelas no universo do trabalho imaterial.

\section{RELAÇÕES PÚBLICAS PARA ALÉM DAS APARÊNCIAS}

Apenas para situar o leitor não familiarizado na área, esclarecemos que as relações públicas se caracterizam como um conjunto de atividades destinadas a planejar e administrar o relacionamento das organizações com os seus públicos, além de cuidar da reputação das mesmas no conjunto da sociedade. Elas são utilizadas para satisfazer as necessidades comunicacionais da organização, da entidade ou do órgão público a que se vinculam. Portanto, como se vê, não estão acima das instituições e dos interesses empresariais e político-ideológicos em jogo, embora sejam constituídas por uma série de premissas que fundamentam sua postura ética e suas práticas operativas.

Em consonância com o que demonstramos no livro Relações públicas no modo de produção capitalista (Peruzzo, 2004), em sua essência as relações públicas nas empresas se juntam a outras estratégias político-organizacionais com a finalidade de harmonizar as relações capital-trabalho, estabelecer clima propenso ao aumento da cooperação e da produtividade do trabalhador, além de angariar o consentimento em torno das estratégias empresariais. No conjunto da sociedade, pela mediação de organizações da sociedade civil e dos governos, elas zelam pela boa reputação das instituições e criam ou reproduzem valores 
favoráveis à produção e reprodução do capitalismo, correspondendo, portanto, aos interesses da classe dominante, a burguesia.

Claro que, de forma geral, elas orientam as instituições quanto à prudência no atendimento efetivo de demandas dos públicos e sobre a necessidade de se corresponder aos interesses da sociedade. Contudo, junto com os benefícios reais cedidos aos públicos, em última instância o que prevalece é o interesse na consecução das estratégias de mercado e as político-ideológicas.

Se, a serviço das organizações civis sem fins lucrativos, muitas premissas e técnicas, embora se mostrem extremamente aplicáveis, alteram os objetivos, os procedimentos e o propósito final, ou seja, a estratégia ou onde se quer chegar. Em suma, o ponto de partida e de chegada dessas entidades é a democratização da cidadania.

Esses aspectos são aqui apontados em razão da forma ambígua com que as relações públicas são tratadas na produção teórica. Por um lado, lhes é atribuída condição de estabelecer a "compreensão mútua", "entendimento, solidariedade e colaboração"2 e a "interação de interesses legítimos"3 nas relações da organização com seus públicos, com base em princípios simbolizados na "rua de mãos", no fornecimento abundante de informações - verídicas - e com postura ética coerente com suas práticas (em relação a meio ambiente, tratamento dispensado ao público interno, responsabilidade social e assim por diante). Seria esplêndido se as intenções (dos profissionais de relações públicas) e o discurso (deles e das empresas) correspondessem às suas práticas ${ }^{4}$. Com algumas exceções, os recursos do "atendimento" efetivo de demandas dos públicos, da responsabilidade social etc. só se concretizam quando não ameaçam os interesses mercadológicos e políticos das empresas.

Há que se reconhecer que existem antagonismos de classe e divergências de interesses políticos e ideológicos, que patrões e empregados até podem se relacionar muito bem, mas não possuem interesses idênticos, e que as empresas priorizam sempre os interesses do capital. Enfim, se no nível do discurso as relações públicas defendem posturas éticas e condizentes com o interesse público, na prática nem sempre se concretizam dessa maneira. Por outro lado, em parte da bibliografia disponível, especialmente daquela com características de manual, não se esconde a aplicabilidade e a importância das relações públicas para concretização dos interesses das organizações, seja solucionando conflitos ou implementando programas de ação bem planejados das relações com os públicos.

1 Segundo a definição oficial da Associação Brasileira de Relações Públicas (ABRP).

2 Definição geral comum das associações de relações públicas, baseada no Acordo do México (1978).

3 Idem.

4 Ver Bueno (2005). 
Para melhor compreensão de como ocorrem relações sociais de produção no interior das organizações privadas, há que se considerar o modo de funcionamento da sociedade, que, no capitalismo, se estrutura em relações antagônicas entre capital e trabalho (compra e venda da força de trabalho, extração da mais-valia, apropriação privada da riqueza gerada socialmente etc.). O Estado, por sua vez, constituído para garantir os interesses da classe dominante, acaba sendo um guardião das condições favoráveis à reprodução da sociedade em seus mecanismos estruturais. Junto com a sociedade civil ele forma uma superestrutura política, ideológica, coercitiva, repressiva e jurídica capaz de assegurar a ordem e disseminar a ideologia das forças dominantes. E, quando obtém o consenso da sociedade, institui a hegemonia e o papel da burguesia no exercício do poder.

Enfim, nas relações entre capital e trabalho as relações públicas, mesmo ouvindo os trabalhadores e/ou contribuindo para corresponder a seus interesses, servem primordialmente aos interesses das organizações. A partir dos relacionamentos estabelecidos com os funcionários - hoje chamados de "colaboradores" -, visando criar relações de confiança e clima agradável de trabalho, elas contribuem para a geração da mais-valia por meio do aumento da produtividade do trabalho, da cooperação e da potenciação das demais forças produtivas (uso adequado dos recursos tecnológicos e geração de conhecimento, entre outros).

Como dissemos no livro Relações públicas no modo de produção capitalista (2004, p. 69), lançado em 1982, as relações públicas se constituem em

instrumento para condicionar a submissão do trabalho ao capital. (...). Procuram envolver os trabalhadores nos objetivos da empresa como se fossem os seus próprios. Esse envolvimento mental cria condições para que o trabalhador seja alguém que produz mais, motivado pela satisfação pessoal e predisposição à cooperação. Procura-se, pois, potenciar essa força produtiva (a cooperação) para aumentar a produtividade do trabalho e a produção, o que aumenta o trabalho não pago e barateia o valor da força de trabalho, aumentando a exploração.

Pondo de lado a força das atividades de relações públicas (e aquelas desenvolvidas sob as denominações comunicação organizacional, comunicação corporativa, endomarketing, comunicação empresarial, comunicação institucional) no estímulo à cooperação direta no processo de trabalho, elas potenciam outros mecanismos colaborativos dos empregados para com a organização. As relações públicas mostram-se eficazes também em reforçar o conformismo em torno das condições de trabalho que, em última instância, contribuem para o processo de geração de valor, bem como da própria renovação das condições de reprodução das relações capitalistas de produção (o trabalhador e seus filhos continuarão dispostos e disponíveis a vender sua capacidade de trabalho). Em última instância, explora-se a vontade pessoal 
de progredir e a necessidade de manter-se no emprego como forma de submeter o trabalhador aos interesses da organização.

Temos conhecimento de posições contrárias a esse tipo de análise, segundo as quais a empresa não pode ser vista tão criticamente assim, porque, afinal, ela oferece emprego e benefícios e, portanto, representa algo de interesse social amplo e de ganho específico para a mão de obra. Emprego? Sim, claro, é algo fundamental no processo de desenvolvimento, mas não se trata de nenhuma dádiva. Contrata-se mão de obra para fazer dinheiro gerar mais dinheiro e não por preocupação com o bem-estar da classe trabalhadora. Se houvesse esse tipo de preocupação, o capital não teria gerado sistemas que culminaram no desemprego estrutural. Cada vez se contrata menos mão de obra, porque a tecnologia suplanta necessidades humanas em processos produtivos. Portanto, oferecer trabalho (é melhor falar em trabalho e não em emprego, porque nem mais as garantias de contratos com cumprimento das leis trabalhistas são generalizadas) é uma necessidade do capital para se reproduzir, é um lado das relações de cumplicidade já mencionadas.

E os benefícios? Antes de mais nada, estes são formas de salário indireto, ou complemento salarial, por meio das quais se deixa de pagar taxas regulamentadas por leis trabalhistas, se reduzem impostos por meio da dedução do imposto de renda e, ainda por cima, se exploram tais feitos como sendo programas de responsabilidade social ou de empresa cidadã. O retorno esperado em imagem corporativa e em submissão da mão de obra suplanta qualquer outra qualidade que possa estar em questão. $\mathrm{Na}$ verdade, os sistemas de benefícios se convertem em mecanismos para reforçar a submissão dos trabalhadores ao capital, apesar de representarem ganhos para os mesmos. Não menosprezamos as vantagens dos benefícios na forma de serviços de saúde, transporte, vale-refeição, cumprimento de leis trabalhistas (FGTS, férias remuneradas), mas daí a não reconhecer os reais interesses em jogo é ingenuidade.

Passados quase trinta anos da publicação original do livro Relações públicas no modo de produção capitalista e diante das mudanças ocorridas no interior desse modo de organização da sociedade, as quais colocam em cheque as categorias trabalho, valor e capital, cabe perguntar sobre a atualidade ou não desse tipo de interpretação sobre a configuração atual das relações públicas ${ }^{5}$.

5 As ideias a seguir foram originalmente escritas para o texto "Relações públicas: da aparência à essência: abordagem na perspectiva da teoria crítica e do modo de produção capitalista", elaborado para a coletânea Relações públicas: história, teorias e estratégias nas organizações contemporâneas, organizada por Margarida M. Krohling Kunsch (2009). Inicialmente pretendeu-se tão-somente apresentar uma síntese do livro já mencionado, mas, em razão das alterações em curso na sociedade, esboçamos algumas análises procurando atentar para a realidade atual, o que fazemos por meio da presente versão. 


\section{RELAÇÕES PÚBLICAS NO AMBIENTE DE TRABALHO PÓS-FORDISTA}

O modo de produção capitalista se atualiza constantemente como forma de assegurar sua reprodutividade e perpetuação histórica. Nos últimos tempos, o processo de reestruturação ocorre por meio de vários vetores. Segundo Manuel Castells (2000, v.1,p. $21 ; 22 ; 31 ; 36)$, esse movimento de mudança é caracterizado por maior flexibilização de gerenciamento; pela descentralização das empresas e sua organização em redes (tanto internas quanto em suas relações com outras empresas); fortalecimento do papel do capital vis-à-vis ao trabalho, com o declínio concomitante da influência dos movimentos de trabalhadores; individualização e diversificação cada vez maior das relações de trabalho; a incorporação maciça das mulheres na força de trabalho remunerada, geralmente em condições discriminatórias; a intervenção estatal para regular os mercados de forma seletiva e desfazer o Estado de Bem-Estar Social (Welfare State); aumento da concorrência econômica global; e a economia informacional. As mudanças engendram um capitalismo

centrado sobre a valorização de um capital dito imaterial, qualificado também de 'capital humano', 'capital-conhecimento' ou 'capital-inteligência'. Essa mutação se faz acompanhar de novas metamorfoses do trabalho. O trabalho abstrato simples, que, desde Adam Smith, era considerado como a fonte do valor, é agora substituído por trabalho complexo. O trabalho de produção material, mensurável em unidades de produtos por unidades de tempo, é substituído por trabalho dito imaterial, ao qual os padrões clássicos de medida não mais podem se aplicar (Gorz, 2005, p. 15).

Para Yann Mouler-Boutang (2003, p. 38), a mutação é radical, pois se trata de um "rearranjamento de certos elementos que são conservados, mas cuja função sofreu uma reviravolta, como, por exemplo, o papel do trabalho operário, o papel do conhecimento, a função do mercado, a relação com a técnica”.

A hipótese geral (Lazarato e Negri, 2001; Cocco, 2001, 2003; Mouler-Boutang, 2003; Corsani, 2003) é que nas últimas duas décadas tem ocorrido mutação estrutural no capitalismo, em que o pós-fordismo desemboca no capitalismo cognitivo. Nas palavras de Antonella Corsani (2003, p. 15 - grifo da autora), a hipótese "é que as transformações em curso não constituem mutações do paradigma do capitalismo industrial. Elas põem em evidência a passagem do capitalismo industrial a algo que poderíamos denominar $c a-$ pitalismo cognitivo". Esta hipótese se sustenta "na perspectiva de uma transformação radical das formas de produção, acumulação e organização social abertas pelas NTIC”6 (Cocco, 2003, p. 8).

A transição do fordismo ao pós-fordismo "pode ser lida como a passagem de uma lógica de reprodução a uma lógica da inovação, de um regime de repe-

6 Novas tecnologias de informação e comunicação. 
tição a um regime de invenção" (Corsani, 2003, p. 15). Para a autora (2003, p. 17), a inovação que já existia como exceção torna-se regra. Referindo-se a $\mathrm{H}$. Bergson $^{7}$, ela (2003, p. 15) mostra que a valorização repousa sobre o conhecimento, sobre o tempo de sua produção, de sua difusão e de sua socialização que as NTIC permitem, enquanto tecnologias cognitivas e relacionais.

O paradigma pós-fordista supera o fordismo no sentido em que se qualifica pela

integração produtiva dos consumidores como produtores, pois eles participam da produção, desde o momento da concepção, em dois níveis: pela integração em tempo real dos comportamentos de consumo; e pela proliferação disseminada dos atos criativos, linguísticos e comunicativos (Cocco, 2001, p. 87).

Do ponto de vista do trabalho, algumas das diferenças entre o fordismo e pós-fordismo são as seguintes: no fordismo o trabalhador é desqualificado, executa mecanicamente as tarefas, o indivíduo é pré-programado e trabalha silenciosamente; ao silêncio do ateliê corresponde o barulho mecânico da produtividade. No pós-fordismo o trabalhador é polifuncional, trabalha falando e tomando iniciativas aleatórias e imprevisíveis, a produtividade - não mais mensurável - depende da integração de fluxos comunicacionais (Cocco, 2001, p. 91). Em outras palavras, é sobre a "derrota do operário fordista e sobre o reconhecimento da centralidade do trabalho vivo sempre mais intelectualizado que se constituíram as variantes do modelo pós-fordista" (Lazzarato; Negri, 2001, p. 25).

Quanto ao trabalho imaterial, característico do capitalismo cognitivo, ele se encontra no cruzamento (é a interface) da "nova relação produção/consumo. É o trabalho imaterial que ativa e organiza (...) [essa relação]. A ativação, seja da cooperação produtiva, seja da relação social com o consumidor, é materializada dentro e através do processo comunicativo” (Lazzarato; Negri, 2001, p. 45).

Como dizem Maurizio Lazzarato e Antonio Negri (2001, p. 45), todas as características da economia pós-industrial (presentes tanto na indústria quanto no setor terciário) são acentuadas na forma da produção "imaterial”. O trabalho imaterial

é reconhecido como base fundamental da produção; este processo não investe somente a produção, mas a forma inteira do ciclo 'reprodução-consumo': o trabalho imaterial não se reproduz (e não reproduz a sociedade) na forma de exploração, mas na forma de reprodução da subjetividade (Lazzarato; Negri, 2001, p. 30).

Nesta perspectiva, os autores (2001, p. 45) ressaltam a importância da comunicação na sociedade contemporânea, uma vez que "a produção audiovisual,

7 No livro L'évolution créatrice. Paris: PUF, 1989. 
a publicidade, a moda, a produção de software, a gestão do território etc.", ao que podemos acrescentar o marketing e as relações públicas, são definidos por meio da relação particular que a produção mantém com o seu mercado e os seus consumidores. Os trabalhadores imateriais (aqueles que trabalham na publicidade, na moda, no marketing, na televisão, na informática etc.) satisfazem demandas do consumidor e ao mesmo as constituem. "O fato de que o trabalho imaterial produz ao mesmo tempo subjetividade e valor econômico demonstra como a produção capitalista tem invadido toda a vida" (Lazzarato; Negri, 2001, p. 47).

Da maneira como são apresentados os novos paradigmas do capitalismo, à primeira vista parece haver a superação total das formas de produção capitalista consolidadas ao longo da história. Mas, como Maurizio Lazzarato e Antonio Negri (2001, p. 59) afirmam, "é evidente que o modo de produção fordista e seus sujeitos não desapareceram. (...). O ponto é que, como sempre, o modo de produção capitalista é um conjunto de diversos modos de produção comandados pelo mais dinâmico e desterritorializado”.

A seguir evidenciamos alguns exemplos de como as mudanças antes anunciadas não afetam no mesmo grau de intensidade todos os países e unidades produtivas ao mesmo tempo, nem eliminam processos de trabalho de produção material. Produtos continuam necessitando de mão de obra humana para sua produção. Novas formas de gestão do capital, como o deslocamento do comando direto dos capitalistas e a descentralização (ou desterritorialização) do processo produtivo (produção de componentes e linhas de montagem podem se efetivar em diferentes espaços geográficos), ou mesmo a produção terceirizada, não descartam a exploração de mão de obra. Aliás, por meio de pequenas e médias empresas locais, ou do "indivíduo-empresa", as corporações migram a produção para países em que ainda podem praticar a exploração da mais-valia até nos moldes do século XIX, como pode ser comprovado pelos estudos de Naomi Klein (2002, p. 230): "o dia de trabalho é longo - 14 horas no Sri Lanka, 12 horas na Indonésia, 16 no sul da China, 12 nas Filipinas”.

A grande maioria dos trabalhadores é composta de mulheres, sempre jovens, sempre trabalhando para contratados ou subcontratados da Coreia, de Taiwan ou de Hong Kong, que, em geral, atendem pedidos de empresas sediadas nos Estados Unidos, na Grã-Bretanha, no Japão, na Alemanha ou no Canadá. Nessas zonas de processamento de exportação (ZPEs) e de livre comércio, "o gerenciamento tem estilo militar, os supervisores cometem abusos, os salários ficam abaixo do nível de subsistência e o trabalho exige pouca habilidade e é tedioso" (Klein, 2002, p. 230). Um estudo de 1998 sobre a fabricação de marcas famosas nas zonas econômicas especiais chineses "revelou que a Wal-Mart, a Raph Lauren, Ann Taylor, Esprit, Liz Claiborne, Kmart, Nike, Adidas, J. C. Penney e The Limited estavam pagando apenas 13 centavos de dólar por hora”, enquanto nos Estados Unidos e na Alemanha, onde as multinacionais fecharam centenas de fábricas têxteis domésticas e transferiram a produção 
para as zonas de exportação, "os trabalhadores do setor vestuário ganham em média US\$ 10 e US\$18,50 por hora, respectivamente (Klein, 2002, p.236-237).

Há ainda o agravante da exploração de mão de obra infantil: "crianças paquistanesas (...) recebendo 6 centavos de dólar por hora” na produção de bolas Nike. "Adidas, Reebook, Umbro, Mitre e Brine fabricavam bolas no Paquistão, onde cerca de 10.000 crianças trabalhavam na indústria, muitas delas vendidas como mão de obra escrava sob contrato a seus empregadores e marcadas como gado" (revista Life, 1996, apud Klein, 2002, p. 356).

Essa realidade não é para os brasileiros algo estranho e distante. A imprensa volta e meia divulga a identificação de exploração de mão de obra nos moldes do trabalho escravo ${ }^{8}$ pelo país afora. Imigrantes de países irmãos, como Bolívia, Paraguai e Peru, são explorados com baixos salários, extensas jornadas e condições de trabalho insalubres na cidade de São Paulo.

Os imigrantes bolivianos fazem turnos de até 16 horas em confecções de roupas nos bairros do Brás, Pari e Bom Retiro. O ambiente de trabalho é fechado, sem janelas e com pouca luz. Os bolivianos moram nas fábricas e precisam pagar tudo para o patrão, desde a máquina de costura [em] que trabalham até a água, luz e comida. Por isso, acabam endividados e 'presos' nas confecções. Para garantir que os imigrantes não fujam, além de trancarem as portas das fábricas, os patrões ameaçam chamar a Polícia Federal para deportar aqueles em situação ilegal (Varella, 2005, on-line).

Esses exemplos parecem confirmar a constatação de André Gorz (2005, p. 15) - na mesma linha de Lazzarato e Negri - de que "atravessamos um período em que coexistem muitos modos de produção". Ou seja, simultaneamente ao trabalho imaterial persiste a produção de bens em larga escala - que depende do trabalho material - (ou de onde viriam os valores de uso de que necessitamos na vida cotidiana?) e continua explorando a mão de obra em linhas de montagem, nos escritórios, no comercio e assim por diante. A informatização e o imaterial afetam a categoria valor, mas não eliminam a exploração do trabalho.

$\mathrm{Na}$ interface da atuação do marketing e da publicidade, as relações públicas têm papel cada vez mais importante nas atuais configurações do capitalismo. Elas atingem direta ou indiretamente toda a sociedade, por meio das relações com os públicos, no sentido da constituição de subjetividades tanto no nível da produção como no do consumo. O modo como os consumidores percebem a

8 "0 trabalho escravo contemporâneo pode ser caracterizado como aquele em que o empregador sujeita 0 empregado a condições de trabalho degradantes e o impede de desvincular-se de seu 'contrato'. A retenção de salários, a violência física e moral, a fraude, o aliciamento, o sistema de acumulação de dívidas (principal instrumento de aprisionamento do trabalhador), as jornadas de trabalho longas, a supressão da liberdade de ir e vir, o não-fornecimento de equipamentos de proteção, a inexistência de atendimento médico, a situação de adoecimento, o fornecimento de água e alimentação inadequadas para consumo humano, entre outros, são elementos associados ao trabalho escravo contemporâneo" (Araujo, s/d., on-line). 
empresa (sua reputação), a marca e seus produtos, por exemplo, não é resultado apenas do trabalho publicitário e do marketing, mas também das relações públicas. No nível interno as relações públicas também atuam no sentido de alimentar as subjetividades, promover a fidelização e gerar laços de cumplicidade dos trabalhadores com os objetivos da empresa e criar identidades com a cultura organizacional que se procura cultivar. Exemplo: a incorporação do espírito de inovação para que a empresa possa ser competitiva, crescer e superar os obstáculos concorrenciais.

Conforme apontado anteriormente, as relações capital-trabalho na economia informacional são alteradas graças ao uso das poderosas tecnologias da informação e das formas organizacionais facilitadas pelos novos meios tecnológicos de comunicação. As alterações provocam a redução de custos de mão de obra e se manifestam em: a) reunião da mão de obra para tarefas específicas em qualquer lugar, a qualquer momento, e sua dispersão quando se desejar; b) individualização do processo de trabalho (as tecnologias da informação possibilitam ao mesmo tempo a descentralização das tarefas e sua coordenação em rede interativa em tempo real, seja entre continentes, seja entre andares de um mesmo edifício); c) centralização do trabalho na realização do valor, mas submetendo os trabalhadores a situações vulneráveis; d) enfraquecimento do poder de barganha dos sindicatos por concessões a que são obrigados a fazer; e) aumento da produtividade e da lucratividade, mas com os trabalhadores perdendo proteção institucional e ficando cada vez mais dependentes das condições individuais de negociação e de um mercado de trabalho em mudança constante (Castells, 2000, v. 1, p. 285-298).

É um contexto em que as mudanças engendradas pelo capitalismo característico da "sociedade do conhecimento" - ou, melhor, da "sociedade da inteligência" (knowledge para os ingleses) - evidenciam o "conhecimento como força produtiva principal”. Se bem que o próprio Marx, em Salário, preço e lucro (s / d, v. 3, p. 355), já apontava os "inventos pelos quais a ciência (...) desenvolve o caráter social e cooperativo do trabalho" como um dos fatores que aumenta a força produtiva e modifica a produtividade do trabalho. Nos Grundrisse ele foi ainda mais claro ao destacar "a crescente importância da aplicação da ciência no processo produtivo constituindo o conhecimento social geral uma força produtiva imediata” (Marx, apud Sierra, 2006, p. 167).

$\mathrm{Na}$ "sociedade da inteligência", segundo Gorz (2005, p. 29),

os produtos da atividade social não são mais (...) produtos do trabalho cristalizado, mas sim do conhecimento cristalizado. [Este,] diferente do trabalho social geral, é impossível de traduzir e de mensurar em unidades abstratas simples. Ele não é redutível a uma quantidade de trabalho abstrato de que ele seria equivalente, o resultado ou o produto. Ele recobre e designa uma grande diversidade de capacidades heterogêneas, ou seja, sem medida comum, entre as quais o julgamento, a intuição, o senso estético, o nível de formação e 
informação, a faculdade de aprender e de se adaptar a situações imprevistas; capacidades elas mesmas ocupadas por atividades heterogêneas que vão do cálculo matemático à retórica e à arte de convencer o interlocutor; da pesquisa técnico-científica à invenção de normas estéticas.

É o universo do trabalho imaterial tido como "o coração, o centro da criação de valor" (Gorz, 2005, p. 19), enquanto o "trabalho material é remetido à periferia do processo de produção. (...) Ele se torna um momento subalterno desse processo, ainda que permaneça indispensável ou mesmo dominante do ponto de vista qualitativo". (...) "O trabalho imaterial é levado a efeito pela inteligência, imaginação e saber. Estes formam o que se chama de "capital humano". O saber do indivíduo conta mais do que o tempo da máquina. O homem, carregando consigo seu próprio capital [o saber, capacidade de empreender], carrega igualmente uma parte do capital da empresa (Centre des Jeunes Dirigentes, apud Gorz, 2005, p. 16).

É a era do pós-fordismo, na qual os trabalhadores, ao contrário da aplicação de métodos disciplinares rígidos com vistas à execução dos comandos na velocidade das máquinas, "devem entrar no processo de produção com toda a bagagem cultural adquirida nos jogos, nos esportes de equipe, nas lutas, nas atividades musicais, teatrais etc. (Gorz, 2005, p. 19).

O capital percebeu que nessas atividades fora do trabalho "são desenvolvidas sua [do trabalhador] vivacidade, sua capacidade de improvisação, de cooperação" (Gorz, 2005, p. 19). Aos aspectos apontados acima acrescentamos a valorização que as empresas ultimamente têm feito do engajamento dos empregados (ou de candidatos a vagas) em projetos sociais comunitários. Por quê? Justamente porque desenvolvem o espírito colaborativo, o que é apropriado pelo capital na sua extrapolação sutil para o trabalho remunerado. Em razão da premência de se conseguir a cooperação dos empregados assalariados na geração do valor (base para a fixação do preço) dos bens materiais (ou não), e que se transforma em valor de troca (preço pelo qual é comercializado), as empresas passam a consumir a força de trabalho dos "colaboradores" e os consideram como parte do seu capital.

"Colaborador"... Eis uma maneira de despistar a relação de submissão do trabalhador ao capital que persiste. É uma forma de anestesiar a pressão constante por resultados competentes, inovadores e rápidos: como "colaborador" da empresa, o assalariado certamente se predispõe mais facilmente a se envolver e a corresponder o máximo possível às demandas da direção, diferentemente do sentimento que experimentaria se se sentisse apenas um "empregado" que não vê a hora de marcar o cartão de ponto de saída. Processo que provoca fadiga e tristeza interior no trabalhador em geral, não compartilhadas abertamente no ambiente de trabalho. Além da pressão direta do próprio ambiente de trabalho, as relações públicas se encarregam de contribuir para criar ambiente favorável à geração desse tipo de subjetividade. 
No nível prático, essas novas formas de explorar o trabalho são justificadas como empreendedorismo individual, que na essência nada mais é do que o interesse em transferir à pessoa o dever de autoproduzir-se, o que tira uma série de obrigações do capital e do Estado. Gilberto Dupas (2005, p. 69) nos ajuda a compreender a questão ao afirmar: "agora, o neoliberalismo inventa o trabalho sem direitos - condição para sua inserção internacional -, obviamente sem reabilitar a luta de classes".

Um olhar mais atento sobre as consequências do alto envolvimento requerido dos "colaboradores" - e em geral correspondido - revela mais um duplo antagonismo. De um lado, a empresa, apesar de camuflar a relação, depende deles para sua prosperidade num ambiente concorrencial incontrolável. Esta é a razão pela qual os considera como parte do seu capital, o que, aliás, revela que o sentido de propriedade sobre a força de trabalho por quem a compra continua vigente na nova fase do capitalismo. Por outro lado, quanto ao trabalhador, que, à primeira vista, pode até se sentir recompensado (psicológica e/ou financeiramente) pelo reconhecimento de seus talentos e de sua virtuosidade por parte de seus supervisores, acaba se envolvendo num processo de servidão voluntária muito maior.

Ao corresponder à pressão pela competência, agilidade e inovabilidade constante, o trabalhador acaba se submetendo a uma dinâmica que usurpa sua individualidade e exige aplicação profissional integral, e não só no momento do trabalho, mas em sua vida como um todo.

No ambiente do trabalho imaterial, a intenção é

fazer baixar na empresa a alma dos trabalhadores”, pois a integração dos ciclos de produção e de reprodução tende a eliminar toda diferença possível entre o tempo de trabalho e o tempo de vida, entre os períodos de emprego e os de formação, entre as atividades produtivas e as improdutivas (Lazzarato e Negri, 2001, p. 108).

Como diz André Gorz (2005, p. 23), o colaborador tenderá a demonstrar que vale mais do que realiza profissionalmente e investirá sua dignidade no exercício gratuito, fora do trabalho, das suas capacidades:

jornalistas que escrevem livros, gráficos do meio publicitário que criam obras de arte, programadores de computadores que demonstram suas habilidades como hakers e como desenvolvedores de programas livres etc.; são muitas as maneiras de salvar sua honra e 'sua alma'.

"Trabalhar" o ambiente organizacional e o modo de pensar do conjunto da sociedade em torno da criação de sentimentos facilitadores de condutas que assegurem a predisposição das pessoas a se sujeitarem a esse tipo de condições de trabalho é tarefa desenvolvida, essencialmente, pelas relações públicas - ou 
outra denominação equivalente -, e pelas demais atividades de comunicação empregadas no ambiente das organizações. Claro que, em nível mais amplo, as instituições de ensino, os meios de comunicação social e demais organizações da sociedade civil e política também participam ativamente do processo de formar pessoas para essa nova realidade.

As relações públicas ajudam a agregar valor aos produtos e às marcas. Trata-se de valor simbólico e imaterial obtido a partir da reputação, ou seja, dos conceitos e das imagens sobre qualidade, eficiência, durabilidade, entre outros, que, juntamente com o marketing, formam ao longo do tempo. Por exemplo, uma marca de refrigerante, ao ser negociada no mercado, o será mais pelo que a marca representa do que pelas fórmulas químicas que detém a propriedade. Por um calçado se paga um valor de troca que inclui valor simbólico que nada mais é do que o valor imaterial (conhecimento mais a publicização de valores agregados).

Jeremy Rifklin (2001, p. 4) atenta para o fato de que o capital intelectual - que ele contrapõe ao capital físico (propriedade de instalações, maquinário etc.) é a força da nova era: "conceitos, ideias e imagens - e não coisas - são os verdadeiros itens de valor na nova economia. A riqueza já não é mais investida no capital físico, mas na imaginação e na criatividade humana.”. As relações públicas participam justamente do processo de formação e consolidação de imagens, conceitos e identidades das corporações junto ao público externo e interno. E, internamente, acresce o seu potencial de agregar elementos facilitadores da colaboração, sujeição, acomodamento de interesses, aumento da produtividade e potenciação das forças produtivas relativas ao conhecimento.

Num outro nível, a importância das relações públicas também se evidencia a partir das redes cibernéticas e de todo o sistema informacional baseado das NTIC. Por exemplo, a divulgação da exploração de trabalho infantil pela Nike rendeu à companhia "milhares de cartas de protesto", "centenas de pequenos e grandes grupos de manifestantes" e "uma dezena de websites críticos", o que deu muito trabalho "ao departamento de relações públicas da Nike" (Klein, 2002, p. 394).

Acresce ainda o fato de se ampliarem a cada dia outros tipos de redes, as sociais e coletivas, expressas em milhares de movimentos que manifestam sinais de contestação e de busca por transformação social, o que vem dando muito trabalho às Relações públicas.

\section{CONSIDERAÇÕES FINAIS}

As mudanças em curso no capitalismo não comprometem a essência da atividade de relações públicas, vista como instrumento que potencia o desenvolvimento das forças produtivas, especialmente o trabalho, e a comunicação 
corporativa como um todo. Da mesma forma, não diminui sua importância na disseminação da informação e da concepção de mundo que leve à domesticação da cultura em torno de um modelo de sociedade acomodado aos movimentos do capitalismo. Pelo contrário, a comunicação - na forma das relações públicas - tende a ser cada vez mais importante em razão da necessidade de diálogo, das interdependências, dos sistemas de redes e da universalidade da cidadania postas em pauta.

Aliás, como toda tese sempre leva a uma antítese, na economia em rede os meios de produção são privatizados, mas ao mesmo tempo contêm considerável potencialidade de serem partilhados. Surge, então, uma nova contradição: as reais condições favoráveis à socialização dos processos produtivos e do saber e a sua privatização. O computador e a internet já se mostram como instrumentos valiosos para a disponibilização dos saberes para o livre acesso público. A privatização do conhecimento - sentido de propriedade privada - já é questionada e o movimento do software livre bem o demonstra.

Ainda no universo das antíteses, algumas manifestações sinalizam mudanças em curso também no nível da sociedade civil, especialmente a partir das forças progressistas, tais como: os movimentos sociais e as organizações da sociedade civil que se apropriam das técnicas e dos demais conhecimentos comunicacionais desenvolvem, cada vez mais, as "relações públicas na contramão", a serviço dos interesses populares; a possibilidade de participação nos lucros como algo já praticado em algumas organizações; a proposta da economia de comunhão e da economia solidária; o empoderamento social das NTIC - criação de sites, blogs etc. e, principalmente, a formação de redes cooperativas e alternativas, colocando a pessoa humana e a questão do planeta como bases de um novo sentido para o desenvolvimento. São temas desafiantes que revelam uma sociedade em constante movimento de mudança e que merecem aprofundamento.

\section{REFERÊNCIAS}

ARAUJO, Marcos de Lima. Pará, o campeão nacional de trabalho escravo. Belém: UFPA, [s./d.]. Disponível em: <www.ufpa.br/ beiradorio/arquivo/Beira22/opiniao.htm >. Acesso em: 21 dez. 2006.

BUENO, Wilson da Costa. Comunicação empresarial no Brasil: uma leitura crítica. São Paulo: Comtexto / All Print, 2005.

CASTELLS, Manuel. A era da informação: economia, sociedade e cultura. A sociedade em rede. Vol. 1. 3. ed. São Paulo: Paz e Terra, 2000

COCCO, Giuseppe. Trabalho e cidadania: produção e direitos na era da globalização. 2. ed. São Paulo: Cortez, 2001.

COCCO, Giuseppe; SILVA, Gerardo; GALVÃO, Alexander P. Introdução: conhecimento, inovação e redes de redes. In: GALVÃo, Alexander P.; SILVA, Gerardo; COCCO, Giuseppe (Org.). Capitalismo cognitivo: trabalho, redes e inovação. Rio de Janeiro: DP\&A, 2003. p. 7-14.

CORSANI, Antonella. Elementos de uma ruptura: a hipótese do capitalismo cognitivo. In: GALVÃO, Alexander P.; SILVA, Gerardo; COCCO, Giuseppe (Org.). Capitalismo cognitivo: trabalho, redes e inovação. Rio de Janeiro: DP\&A, 2003. p. 15-32.

DUPAS, Gilberto. Atores e poderes na nova ordem global: assimetrias, instabilidades e imperativos de legitimação. São Paulo: Unesp, 2005. 
GALVÃO, Alexander P.; SILVA, Gerardo; COCCO, Giuseppe (Org.). Capitalismo cognitivo: trabalho, redes e inovação. Rio de Janeiro: DPGA, 2003.

GORZ, André. 0 imaterial: conhecimento, valor e capital. São Paulo: Annablume, 2005.

KLEIN, Naomi. Sem logo: a tirania das marcas em um planeta vendido. Tradução de Ryta Vinagre. Rio de Janeiro: Record, 2002.

LAZZARATO, Maurízio; NEGRI, Antonio. Trabalho imaterial: formas de vida e produção da subjetividade. Rio de Janeiro: DP\&A, 2001.

MARX, Karl. Contribuição à crítica da economia política. São Paulo: Martins Fontes, 1977.

. Salário, preço e lucro. In: MARX, Karl; ENGELS, Friedrich. Textos. São Paulo: Edições Sociais, v. 3, [s/d]. p. 333-378.

MOULIER-BOUTANG, Yann. 0 território e as políticas de controle do trabalho no capitalismo cognitivo. In: GALVÃ0, Alexander P.; SILVA, Gerardo; COCCO, Giuseppe (Org.). Capitalismo cognitivo: trabalho, redes e inovação. Rio de Janeiro: DP\&A, 2003. p. 33-60.

PERUZZO, Cicilia M. Krohling. Relações públicas no modo de produção capitalista. 4. ed. São Paulo: Summus, 2004.

RIFKLIN, Jeremy. $A$ era do acesso: a transição de mercados convencionais para networks e o nascimento de uma nova economia. Tradução de Maria Lucia G. L. Rosa. São Paulo: Makron Books, 2001.

SIERRA CABALLERO, Francisco. Trabajo inmaterial y crítica ómico-política del capitalismo cognitivo. Redes.Com - Revista de Estudios para el Desarrollo Social de la Comunicacion, n. 3, p. 165-169, 2006,. Sevilla: Instituto Europeo de Comunicacion y Desarrollo.

VARELLA, Thiago. Imigrantes bolivianos vivem como escravos em São Paulo. Espaço Cidadania, n. 26, 2005. São Bernardo do Campo: Umesp. Disponível em: <www.metodista.br/cidadania/numero-26/imigrantes-bolivianos-vivem-como-escravos-em-sao-paulo>. Acesso em: 21 dez. 2006.

Recebido em: 24.10.2011 / Aceito em: 17.11.2011 